\title{
ERP Implementation Approaches: A Comparative Study
}

\author{
Amr Ahmed Fetouh \\ High Institute for Computers \\ and Information Systems \\ Al Shorouk Academy \\ Cairo - Egypt \\ e. mail: amr_casper111@hotmail.com
}

\author{
Dr. Ahmed el Abbassy \\ High Institute for Computers \\ and Information Systems \\ Al Shorouk Academy \\ Cairo - Egypt \\ e. mail: ahmed_elabbassy@yahoo.com
}

\author{
Dr. Ramadan Moawad \\ High Institute for Computers \\ and Information Systems \\ Al Shorouk Academy \\ Cairo - Egypt \\ e. mail: rammoawad@yahoo.com
}

\begin{abstract}
Enterprise Resource Planning (ERP) software is an integrated application module based package which covers most of the business process and functions of an enterprise. ERP systems are widely being used by industries. However, the results of the research efforts carried out in this field reveal that the rate of successful implementations for ERP projects is low and in most cases the planned goals are not achieved. There are many different implementation approaches and each approach has its defects that may cause increasing in the implementation cost and time and may affect the implementation quality. The most two common ERP implementation approaches are Big bang implementation approach and Agile implementation approach. In recent research work we proposed a hybrid approach to avoid the disadvantages for these approaches. In this paper we propose a method to compare ERP implementation approaches and we used it to demonstrate the benefits of the new hybrid approach. An experimental study was conducted to evaluate the different implementation approaches.
\end{abstract}

Key words: Agile process, ERP life cycle, ERP implementation approaches, Legacy system, Software Engineering 


\section{Introduction}

Enterprise Resource Planning (ERP) systems are enterprise wide systems which, integrate and automate all of company's business processes. ERP systems are large information systems that cover business processes such as sales, production, logistic and Financial [1, 13].

The framework of ERP life cycle is structured into phases and dimensions. Figure 1 illustrates ERP phases and dimensions [2, 3]. ERP phases are adoption decision phase, acquisition phase, implementation phase and maintenance. ERP dimensions are change management, people and process. Adoption decision phase includes the definition of system requirements, its goals and benefits and an analysis of the impact of adoption at a business and organization level. Package selection consists of the product selection that best fits the requirements of the organization. Implementation phase includes installing software and hardware, train users, connect to legacy systems and convert data from other systems. Once the system implemented, it must be maintained because malfunctions have to be corrected and general systems improvements have to be made. The goal of process dimension is to achieve better performance by reengineering business processes. People skills and roles must be developed to reduce risk and manage complexity. The change management dimension tries to ensure the acceptance and readiness of the new system.
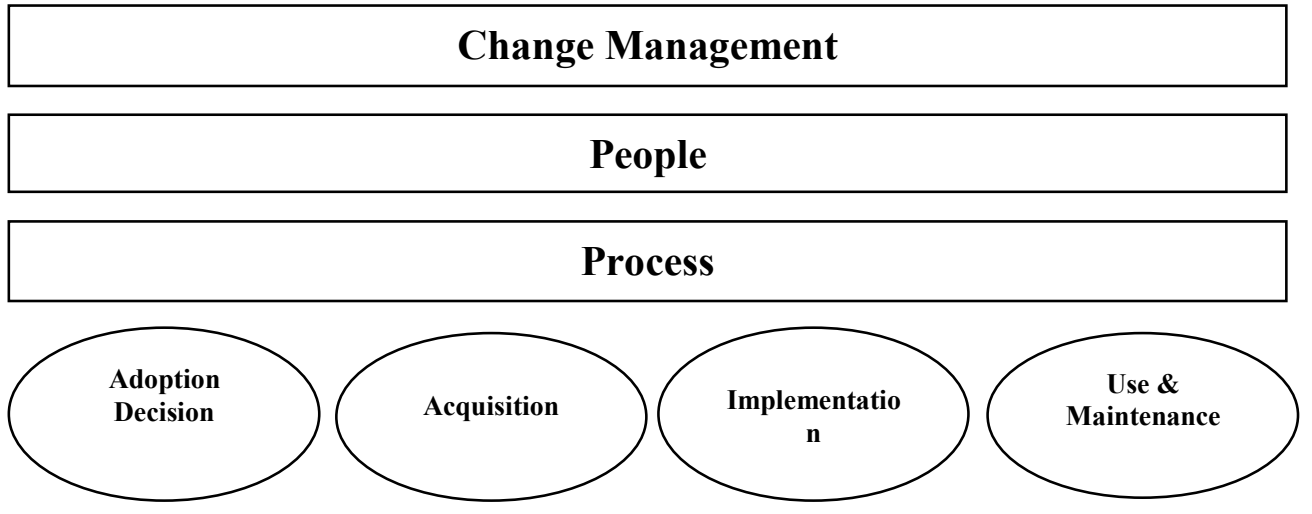

Figure 1: ERP Lifecycle

The first two stages of ERP life cycle are planning and package selection. Once these stages are completed the implementation stage begins. The implementation stage is the important stage in ERP life cycle because in this stage 
the implementation approach is identified. Each implementation approach has advantages and disadvantages. The most two common ERP implementation approaches are Big bang implementation approach and Agile implementation approach.

It has been widely reported that a large number of ERP implementations fail to meet expectations, over time and over budget. There are many different implementation approaches and each approach has its defects that may cause increasing in the implementation cost and time and may affect the implementation quality.

Recently research efforts were directed towards proposing hybrid approaches that combine both agile and big bang approaches.

In this paper we are addressing the issues of comparing ERP implementation approaches, and a framework for assessing ERP implementation approaches is proposed.

The proposed method has been validated using a suitable case study to compare between Big Bang, Agile and the Hybrid ERP implementation approaches.

The rest of this work is structured as follows: Section 2 presents an overview of ERP implementation approaches. In section 3 the proposed method of comparison is presented and discussed before describing the case study and the experiment in Sections 4, 5 and Section 6 describes the conclusion and future work on this topic.

\section{ERP Implementation Approaches}

Implementation is the method a company uses to achieve their goals by transforming the way they carry out operations. With implementation, software is the tool that is used to achieve this objective. Implementation insures that the software is not only installed, but also meets operational and strategic goal. A successful installation is no guarantee that the ERP system will achieve company goals over a sustained period of time [2,3]. The success of ERP is based on choosing the implementation approach and also implementation project costs and risks are also dependent on the implementation approach chosen by the organization $[4,14,16]$. The most tow common implementation approaches are Big bang approach and Agile approach.

\subsection{Big bang Implementation Approach}

In the big bang implementation approach, the implementation process is divided into distinct phases which are executed in strict order, without a possibility of ever failing back to a previous phase or stage and it is too expensive to undo the 
changes ERP brings to company. So the big bang approach could be called waterfall approach [5].

As illustrated in figure 2, the transition from the legacy system to the new system happens at one single date, the so called instant changeover of the system. The big bang adoption type is too risky because there are fewer learning opportunities incorporated in the approach [6].

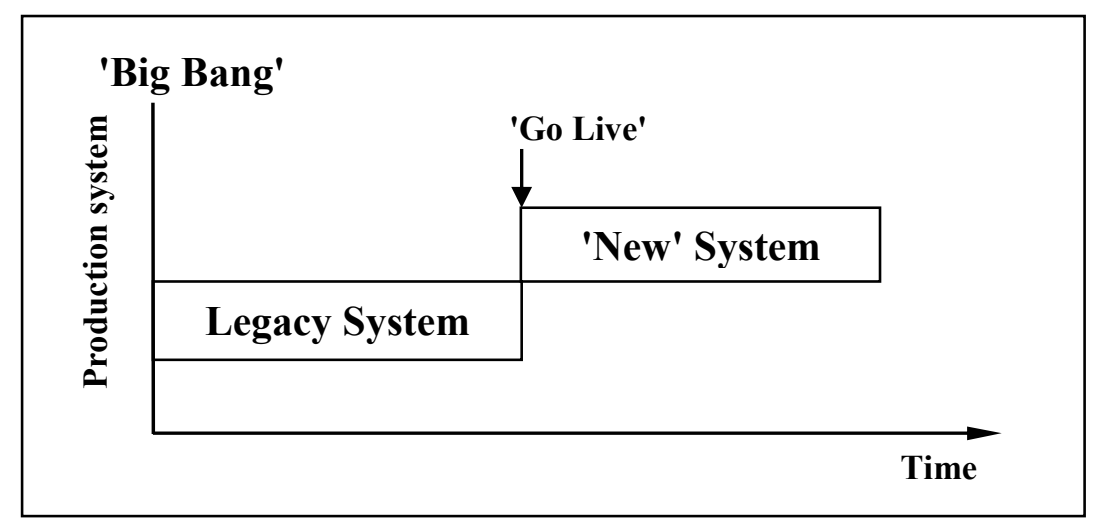

Figure 2: Big Bang Model View

The Big bang process consists from several steps: prepare management, converting the system, releasing parts of ERP system and training the future users. When all the steps are taken, the legacy system will be turned down then the ERP system can be loaded and then will be released. Once the new ERP is released there is no turning back. After introducing the ERP, there usually is a so called initial dip phenomenon which happens because the users are struggling with the new ERP $[7,8]$.

\subsection{Agile Implementation Approach}

With agile approach, the implementation is done in an incremental or phased way. The main promise for agile implementation methodology is to avoid pitfalls and problems associated with big bang implementation approach. Agile is based on the simplicity, to move fast and to deliver operating functionality of the software as fast as possible, starting with the components that are most important for your business. So Agile approach could be called phased implementation approach $[15,17]$. 
Figure 3 shows that the transition from the legacy system to the new system happens at different stages.

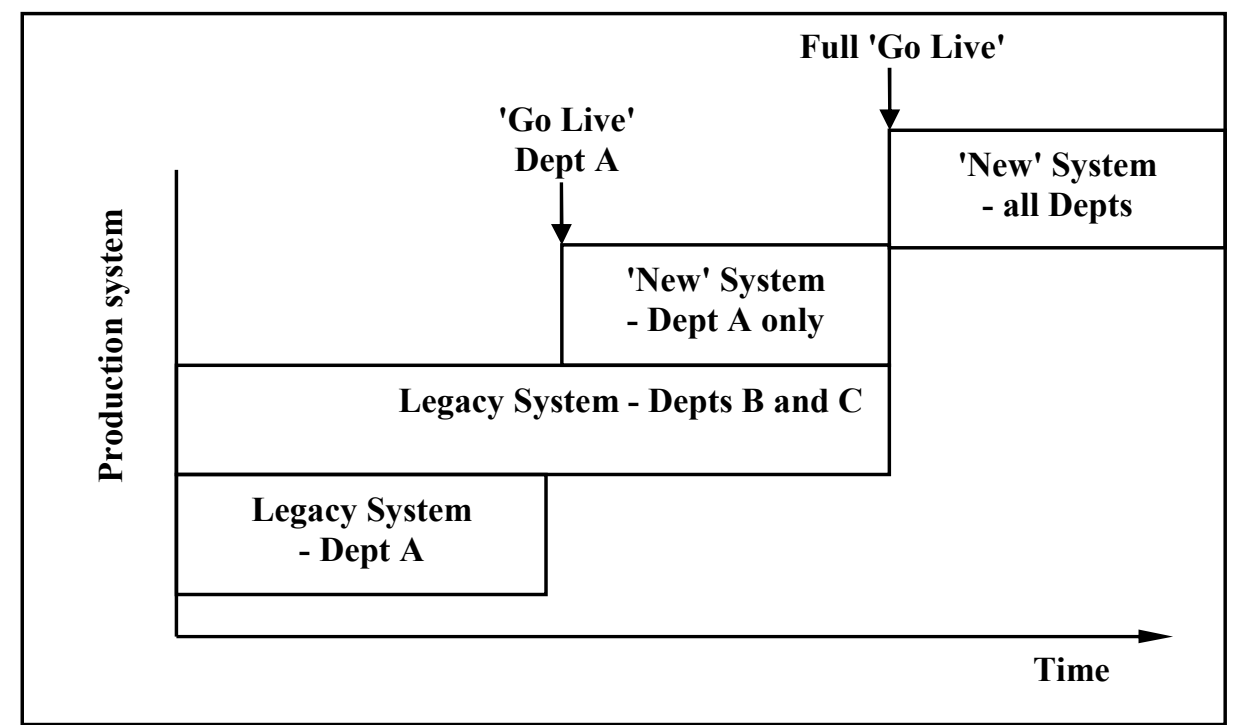

Figure 3: Agile Model View

Agile implementation consists from two phases: Baseline and Sprint realization as shown in figure 4 [9]. Baseline phase consists from four steps:

1) Project preparation in which elements such as roles, responsibilities, documentation standards and hardware requirements are discussed.

2) Envision process workshops in which all operating processes and process dependant conditions such as master data, conversions, security, authorizations, and interfaces are carefully identified. On the basis of the outcomes, this will be translated into a solid foundation for the entire project.

3) Function baseline system, in which based on standard ERP software. As SAP implementation team first makes an inventory of whether project accelerator such as SAP best practices.

4) Evaluation phase, in this phase the business determines the priority of the additional requirements and functionalities the so-called Delta list, in order of business value. 
Sprint realization consists from five steps:

1) Sprint planning meetings at the start of the sprint, the target for the sprint is defined and together with the process owner and the implementation team.

2) Delta realization in which the implementation team realizes the delta requirements and also includes testing and documentation.

3) Daily status meetings, the progress of the project is recorded and any obstacles the team encounter are discussed

4) Sprint demo session, during this phased users and IT can immediately determine whether the processes developed meet the set requirements.

5) Sprint review will also be held to see what can be improved in the following sprint [9].

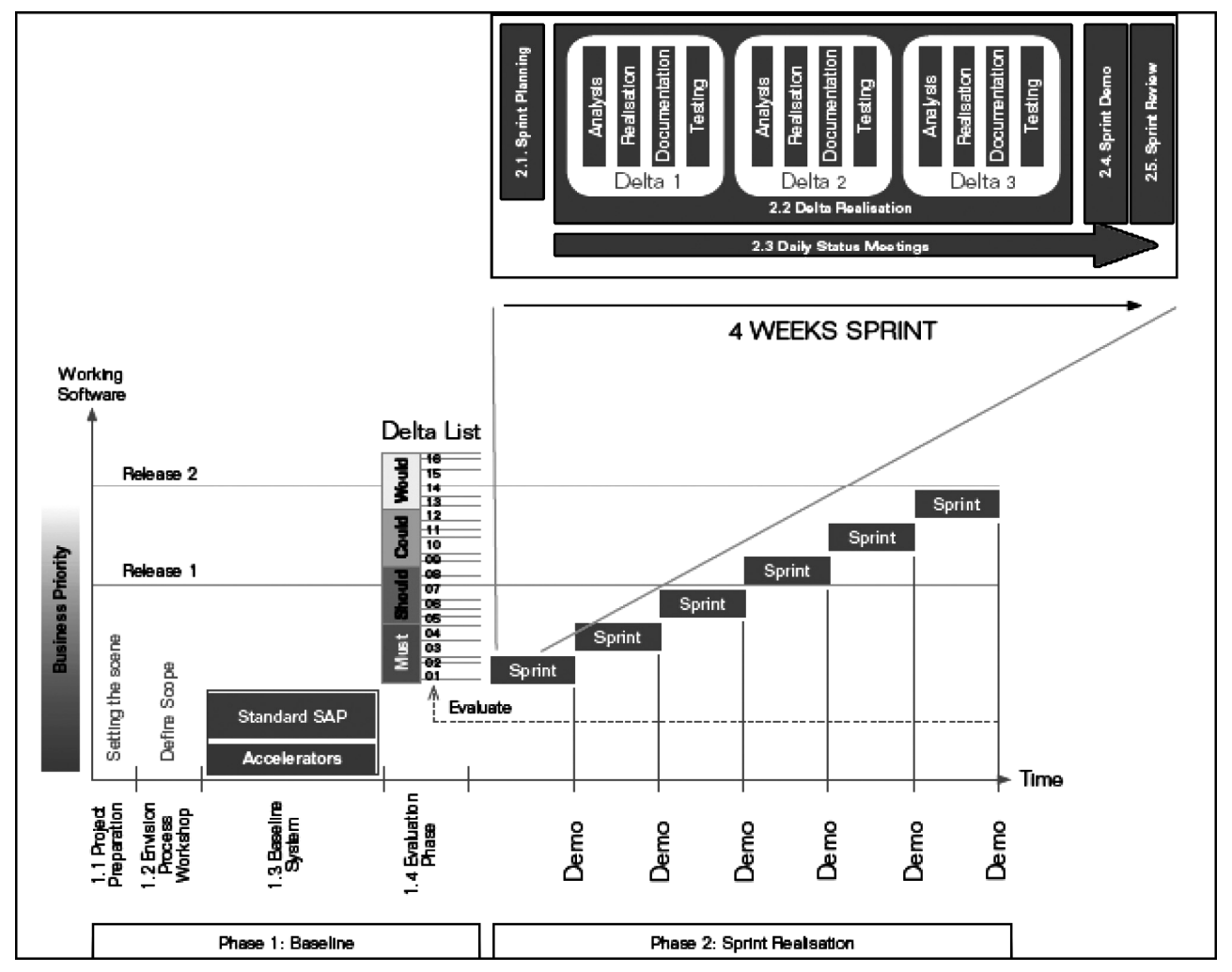

Figure 4: Agile Implementation Approach 
Journal of the ACS, Vol. 5, May 2011

\subsection{Big bang Approach VS. Agile Approach}

Table 1 shows the differences between Big bang approach and Agile approach $[10,11]$.

Table 1: Big Bang Approach VS. Agile Approach

\begin{tabular}{|l|l|}
\hline \multicolumn{1}{|c|}{ Big bang } & \multicolumn{1}{c|}{ Agile or Phased } \\
\hline No need for temporary interfaces & Heavy use of temporary interface $(*)$ \\
\hline Huge peak resources may be required & $\begin{array}{l}\text { Peak resource requirements are low } \\
\text { and more }\end{array}$ \\
\hline $\begin{array}{l}\text { The risk of total system failure may } \\
\text { be higher }\end{array}$ & Low risk \\
\hline Legacy system can't be returned & Legacy system can be returned \\
\hline Users Feedbacks in last phase & Users Feedbacks in each iteration \\
\hline $\begin{array}{l}\text { Time between development and use } \\
\text { is large }\end{array}$ & $\begin{array}{l}\text { Time between development and use is } \\
\text { reduced }\end{array}$ \\
\hline $\begin{array}{l}\text { Limited need to maintain legacy } \\
\text { system }\end{array}$ & $\begin{array}{l}\text { Need to maintain and revise legacy } \\
\text { software }\end{array}$ \\
\hline shorter duration to install & Longer duration to install \\
\hline
\end{tabular}

* Temporary interfaces: These interfaces are required to bridge the gap between the legacy system and new ERP system until the new ERP system becomes fully functional.

\subsection{Hybrid Approach}

Due to the disadvantages in Big bang approach and Agile approach, we need to propose a new methodology to avoid these disadvantages. For Agile as shown in table 1, the main disadvantages are the need for a huge amount of interfaces that will lead to high cost and the implementation may take a long time $[12,18]$. For Big bang implementation, the main disadvantage is the need for a huge resources and falling back is too expensive.

The proposed approach is a hybrid between agile and big bang approach. Hybrid approach is incremental like agile approach but instead of implementing one module by module, the implementation will be cycle by cycle or implement a subset of modules incrementally [13]. Also Hybrid approach is sequential like Big bang approach but sequential in each cycle not all modules in one cycle and not to go live for or all modules at the same time. To implement the hybrid approach we need to construct a dependency diagram for ERP modules. Figure 5 shows the 
dependency diagram that defines the relation between ERP modules and the inputs for each ERP module and the outputs for each ERP module.

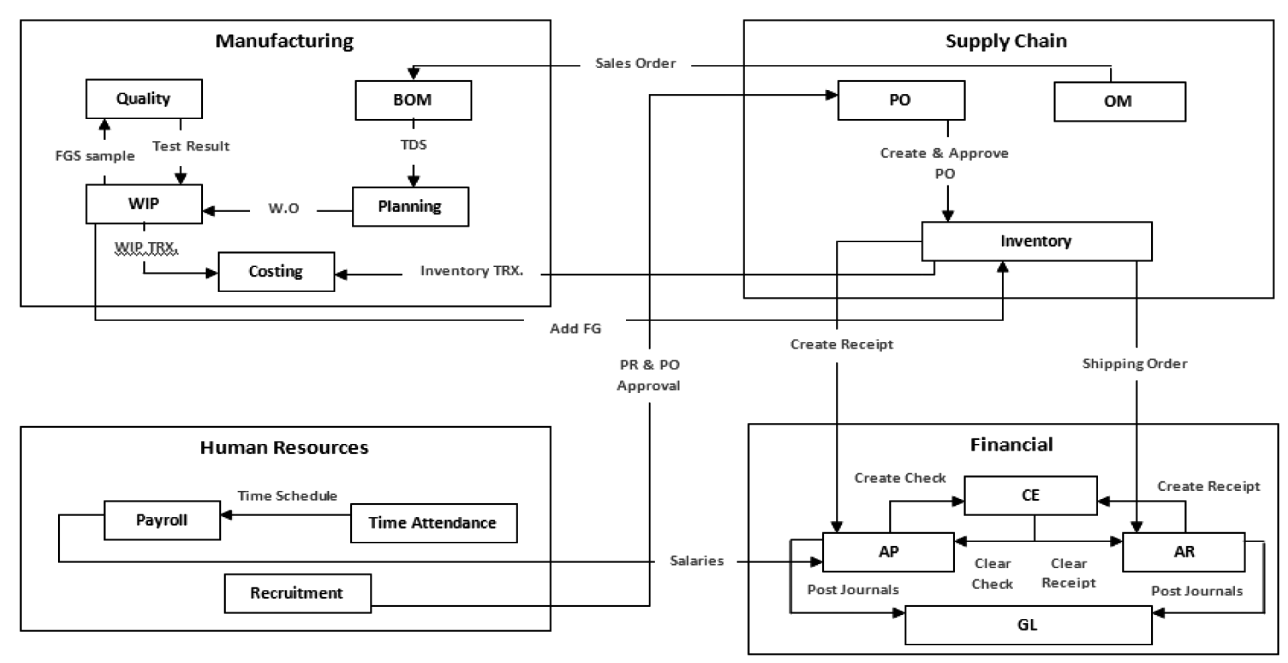

Figure 5: ERP Dependency Diagram

\section{Abbreviations:}

AP: Account Payable, AR: Account Receivable, BOM: Bill of Material, CM:

Cash Management,

FGS: Finish Goods, GL : General Ledger, HR: Human Resources, OM: Order

Management, PO: Purchase Order,

PR: Purchase Requisition, TDS: Transaction Data Sheet, TRX: Transaction,

WIP: Work In Process

The dependency diagram is used to guide the implementation in the Hybrid approach. Figure 6 shows how hybrid approach combines between sequential and incremental implementation in the same time. Sequential is shown in implementing the related sub modules from some modules and going live at the same time per cycle according to the priorities of requirements. For example the first cycle is procure to pay that includes recruitment from human resource module, purchasing from logistic module, payable and general ledger from financial module. The second cycle is order to cash which includes order management from logistic module, receivable from financial module and also general ledger but it's implemented in the first cycle. Incremental is shown in going live at different dates 
for each cycle like $1^{\text {st }}$ live date for procure to pay cycle, $2^{\text {nd }}$ live date for order to cash cycle, $3^{\text {rd }}$ for manufacturing cycle and so on [13].

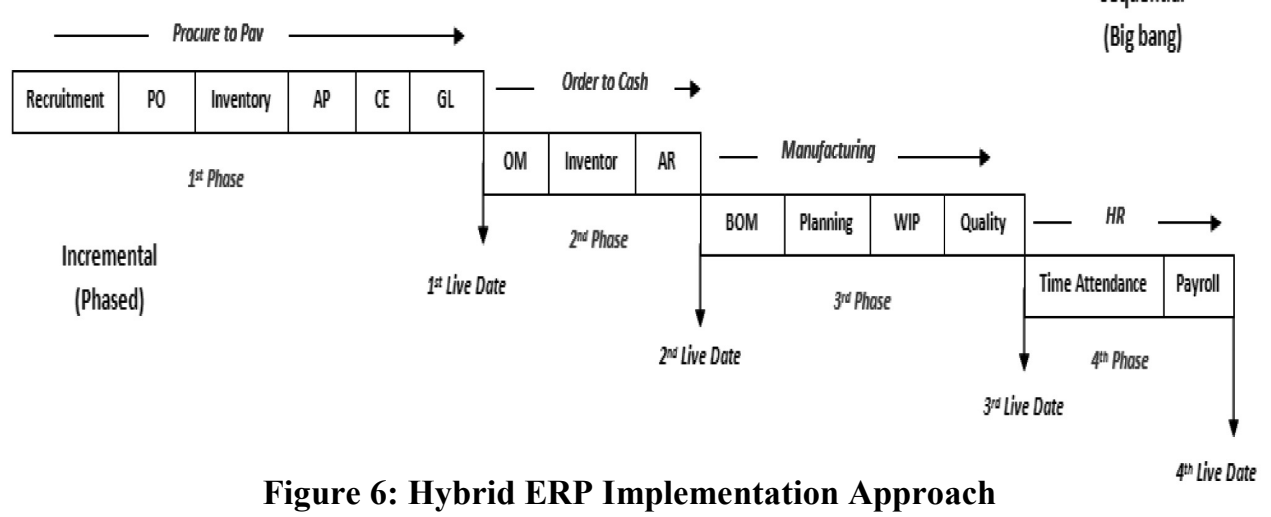

\section{ERP Implementation Approach Assessment Method}

The Comparative analysis between ERP implementation approaches will be based on three types of metrics which are:

1) ERP implementation time

2) ERP implementation cost

3) ERP implementation quality

\subsection{ERP Implementation Time}

ERP implementation time is the time from the beginning of implementation till to going live.

\subsection{ERP Implementation Cost}

\subsubsection{ERP Implementation Cost Models}

The six costing models prevalent in the ERP implementation domain are[19]:

1) Traditional Cost Estimating model

2) Parametric Estimating model

3) Feature Based Costing model

4) Neural Network Based Costing model

5) Case Based Reasoning model

6) Activity Based Costing model

Activity Based Costing ( $\mathrm{ABC}$ ) model is acknowledged in the existing literature as a more accurate costing model that traces expenses to cost-objects [19]. ABC model is certainly an appealing option for ERP implementation as it 
combines the estimates with hard data. In ABC, cost objects consume activities, and activities consume resources. This consumption of resources is what drives the cost. The ABC analysis is the method used to estimate ERP implementation cost in the comparative study.

The five activities that need to be performed in order to determine the activity costs associated a typical ERP implementation are: (i) analysis for the identification of the activities, (ii) gathering costs or determining cost for each activity, (iii) tracing costs to activities or tracing the cost drivers, (iv) establishing output measures or collecting activity data, and (v) analyzing costs for assessing the final cost of ERP implementation.

In order to ensure that all aspects of an ERP implementation are addressed, The WBS (Work Breakdown Structure) will be used to define the ERP project activities [20].

\subsubsection{Cost Drivers}

ERP implementation cost drivers include software license, support cost, internal training, data center cost and consultant cost

1) ERP license and support cost

License Cost $=\sum$ module license price ${ }^{*}[$ Total number of users per module]

Support Cost $=\sum$ module support price * [Total number of users per module]

2) ERP training cost

Training Cost $=$ No. of trainee * number of days * Day price

3) Salary and Bonus for implementation team who are responsible for user training

\section{AVG(sal)* $12 *$ number of implementers}

4) Data center cost

Data center cost include cost of all servers and data center equipment such as: Racks, Network, Switches, Wires, Air- conditioners, Generators, Ups, etc.

5) Consultant cost

Consultants are responsible for administering \& implementing each of the phases of the implementation.

Consultant Cost $=$ No. of consultant* no. of months * consultant cost per month All cost elements are calculated as present value (reference to the project start date) and for the same number of users. 


\subsection{ERP Implementation Quality}

ERP implementation quality includes learning, practical test, knowledge transfer, user satisfaction. The considered factors are:

1) Learning is a factor to evaluate if the users understand how to apply their business requirements on ERP and learned to work on it.

2) Practical test is a factor to evaluate if the users tested their work on ERP and estimate the validation of results from practical test.

3) Knowledge transfer is a factor to estimate if the users negotiated their business requirements with the implementers to arrive to the best way to apply their requirements.

4) User satisfaction is a factor to estimate if the users satisfied from training and implementation.

\section{Case Study Background}

\subsection{Background}

We made a case study on EL-Sewedy Group to compare between Big bang approach, Agile approach and Hybrid approach. EL-Sewedy Group has 3 sectors and all sites are using Oracle E-Business suit.

1) El-Sewedy Cables: is one of the largest private sector cables factory in Egypt.

2) El-Sewedy Iskraemeco: is among the leading world companies in metering products

3) El-Sewedy Transformers: provides several types of transformers products

Table 2 shows each implementation strategy for each company in El-Sewedy Group

Table 2: Companies Implementation Strategies

\begin{tabular}{|l|l|l|}
\hline Code & Company & Implementation Strategy \\
\hline Company A & $\begin{array}{l}\text { El-Sewedy } \\
\text { Iskraemeco }\end{array}$ & Big bang Implementation \\
\hline Company B & El-Sewedy Cables & Agile Implementation \\
\hline Company C & $\begin{array}{l}\text { El-Sewedy } \\
\text { Transformers }\end{array}$ & Hybrid Approach \\
\hline
\end{tabular}

As long as all sites are using Oracle E-Business suit, the key activities that constitute the ERP implementation project were defined based on Oracle AIM (Application Implementation Methodology) [21]. 
ERP Implementation Approaches: A Comparative Study

\subsection{ERP Modules}

Oracle E-Business suit implemented in the case study incorporates the modules and sub-modules illustrated in figure 7.
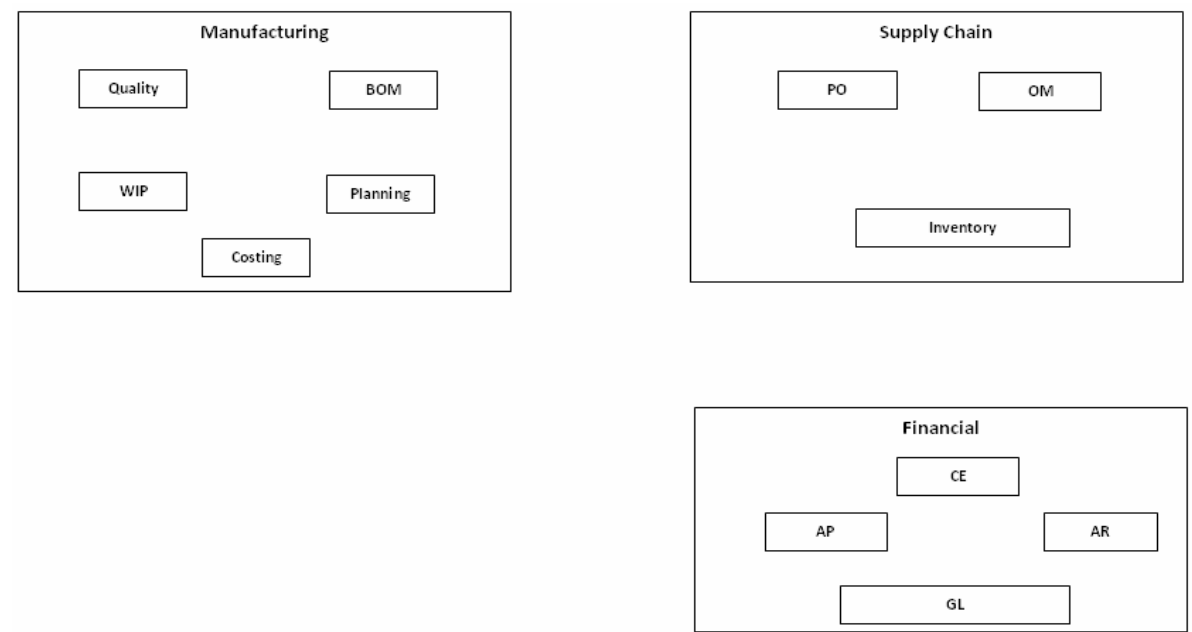

Figure 7: The Implemented ERP Modules and Sub-modules

\subsection{Big Bang Implementation}

ERP was implemented by company A using Big Bang approach as illustrated in figure 8 .

\section{Modules}

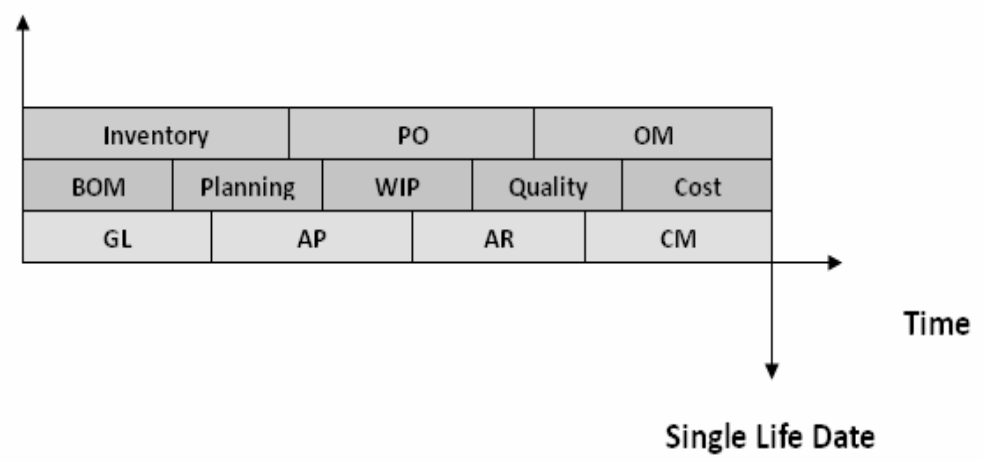

Figure 8 : Company A - Big Bang Implementation 
Journal of the ACS, Vol. 5, May 2011

\subsection{Agile Implementation Approach}

ERP was implemented by company B using Agile approach as illustrated in figure 9.

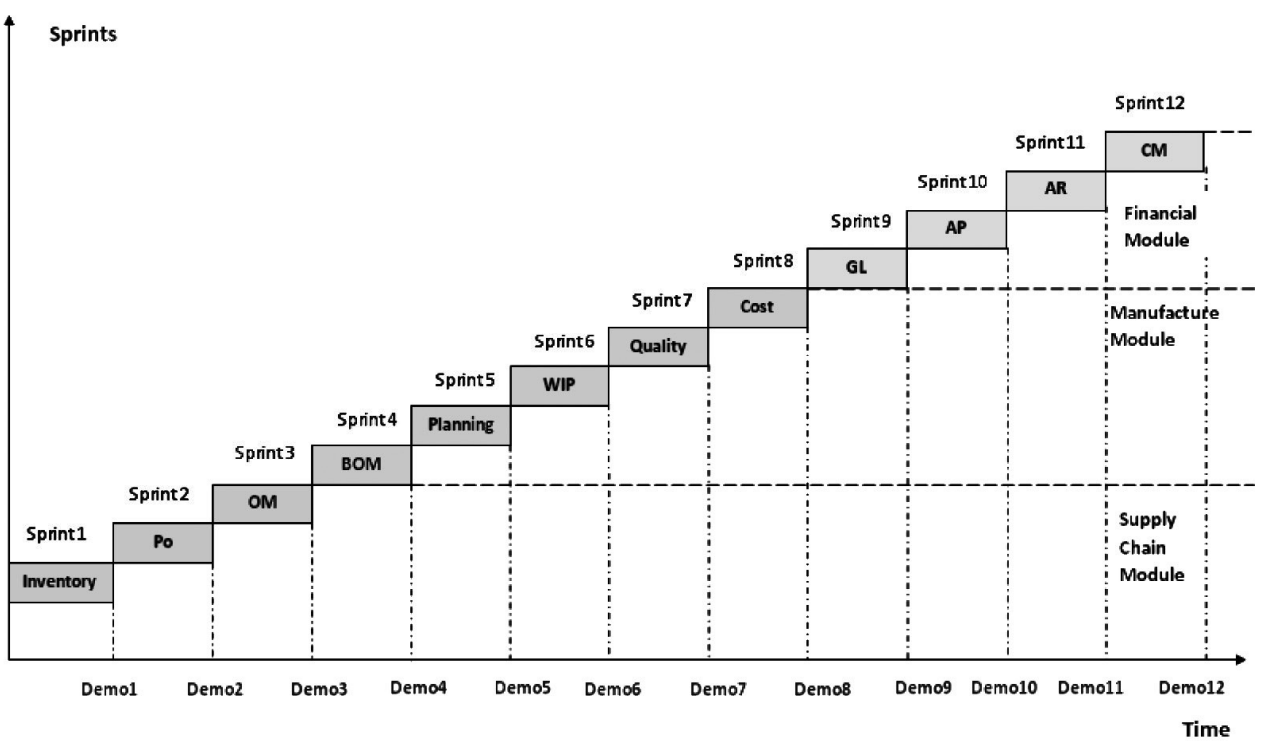

Figure 9 : Company B - Agile Implementation

\subsection{Hybrid Implementation Approach}

ERP was implemented by company $\mathrm{C}$ using Hybrid approach as illustrated in figure 10.

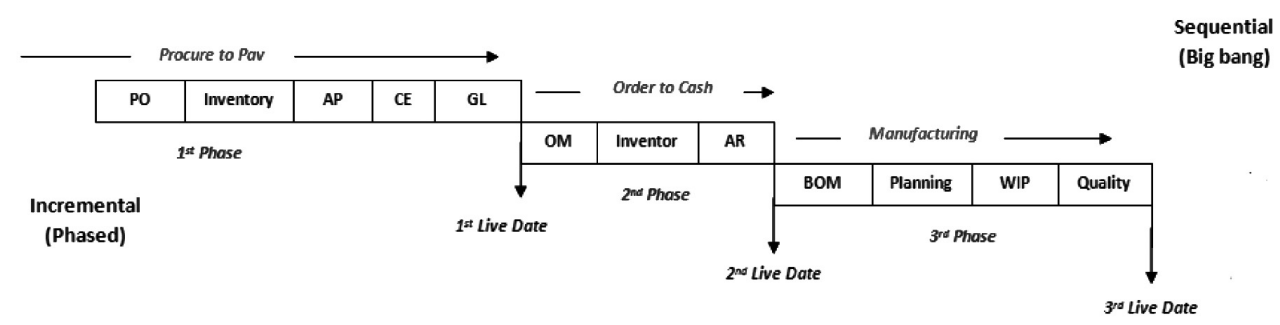

Figure 10: Company C - Hybrid Implementation 
ERP Implementation Approaches: A Comparative Study

\section{Results of the Case Study}

\subsection{ERP Implementation Time}

The implementation time is illustrated in table 3 and Figure 11

Table 3: ERP Implementation Time Per Each Company

\begin{tabular}{|c|c|c|c|}
\hline Company & From & To & Months \\
\hline $\begin{array}{c}\text { Company A-Big } \\
\text { Bang }\end{array}$ & Jun-2010 & Jul-2011 & 13 \\
\hline Company B- Agile & Jan-2004 & Jun-2005 & 18 \\
\hline Company C-Hybrid & Mar-2010 & May-2011 & 15 \\
\hline
\end{tabular}

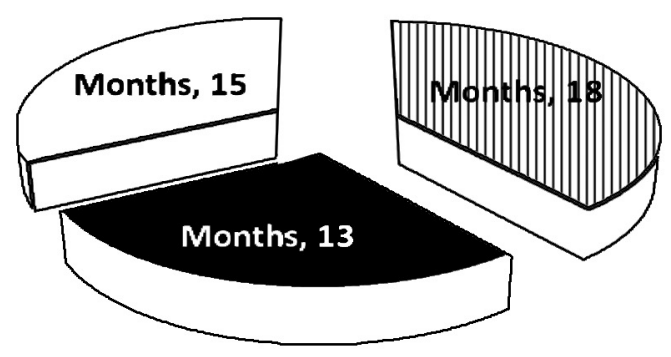

m El-Sewedy Cables (Agile)

El-Sewedy Iskraemeco (Big bang)

$\square$ El-Sewedy Transformers (Hybrid)

Figure 11: ERP implementation time per each company

\subsection{ERP Implementation Cost}

\subsubsection{ERP license and support cost}

For Company A which applied Big bang approach, the cutover of the legacy system happened at one time. So they needed the greatest number of users to handle the work load in a short time. For Company B which applied Agile approach, the implementation done module by module or step by step and the implementation done incrementally. So they needed less number of users than Company A. For Company $\mathrm{C}$ which applied hybrid approach, the implementation is also done incrementally by implementing sub modules instead complete modules like GL from Finance module. So they needed t the smallest number of users.

By substitution in license and support cost equation, we can calculate license and support cost for each company as shown in figure 12 


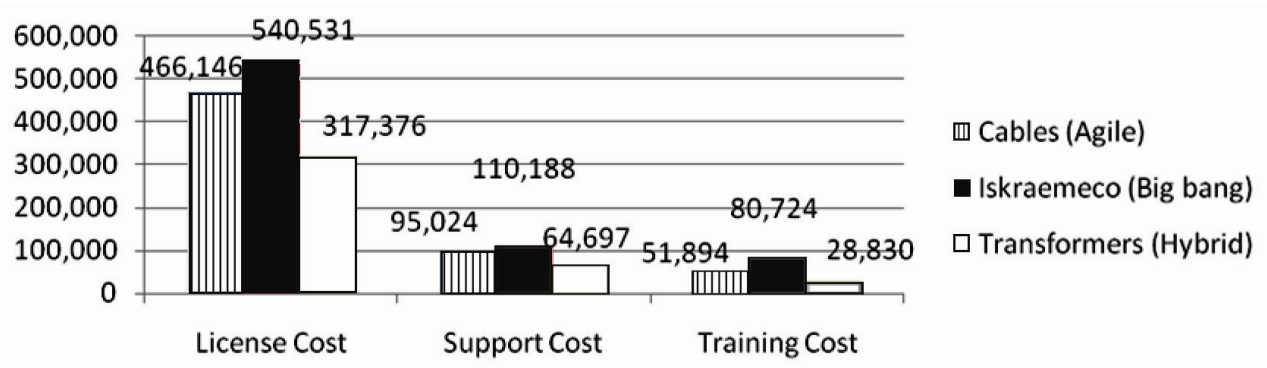

Figure 12: Cost for Each Company According to License, Support and Training

\subsubsection{ERP Training Cost}

To calculate training cost we need to know number of trainee per each company per module

Table 4 shows number of trainees for each company per each module

Table 4: No. of Trainees for Each Company per Each Module

\begin{tabular}{|r|r|r|r|r|r|}
\hline Company & Finance & Inventory & Manufacture & Developers & DBA \\
\hline Company A & 3 & 3 & 3 & 3 & 2 \\
\hline Company B & 2 & 2 & 2 & 2 & 1 \\
\hline Company C & 1 & 1 & 1 & 1 & 1 \\
\hline
\end{tabular}

For Company A which applied Big bang approach, the cutover of the legacy system happened at one time. So they needed to the greatest number of implementers to handle the work load in a short time.

For Company B which applied Agile approach, the implementation done module by module or step by step and the implementation done incrementally. So they needed a smaller number of implementers than company A who may be distributed on different sub modules like GL, AP, AR, CM from Finance and so on.

For Company $\mathrm{C}$ which applied hybrid approach, the implementation is also incremental by implementing sub module instead of complete module like GL from Finance module. So they needed to the smallest number of implementers.

By substitution in training cost equation, we can calculate training cost for each company as shown in figure 12 . 


\subsubsection{Salary and Bonus for implementation team}

Figure 13 shows total salary's for each company based on the number of implementers.

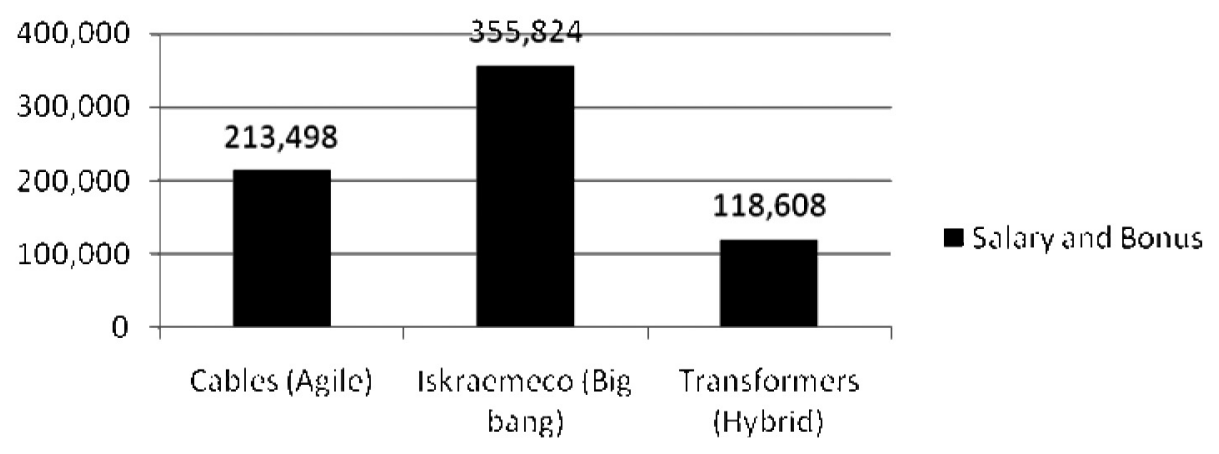

Figure 13: Total Implementers Salary

\subsubsection{Analysis of Data center cost}

Because Company $\mathrm{C}$ is using hybrid approach, the data center cost is paid at different installments because the implementation is done cycle by cycle. So you will have the ability to adjust data center size and upgrade it at different stages and also the payment of the cost could be done at different stages.

\subsubsection{Consultant Cost}

By substitution in consultant cost equation, we can calculate consultant cost for each company as shown in figure 14

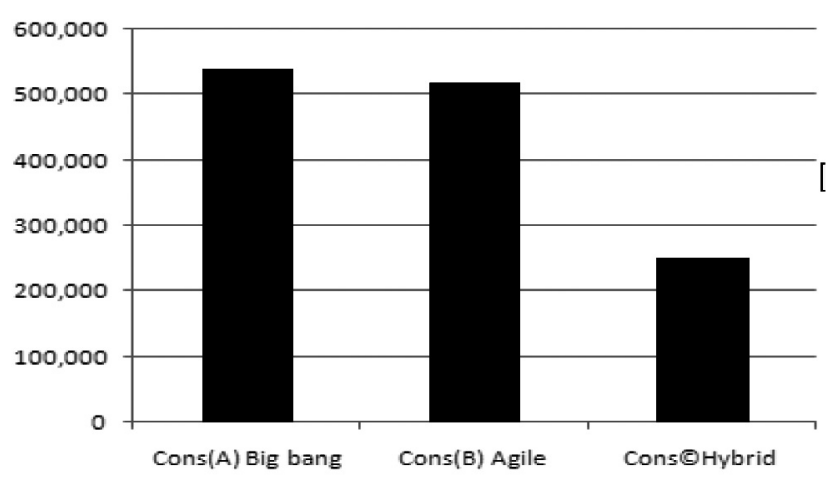

Figure 14: Consultant Cost 
For Company A which applied Big bang approach, the cutover of the legacy system happened at one time. So they needed to the greatest number of consultants to handle the work load in a short time.

For Company B which applied Agile approach, the implementation done module by module or step by step and the implementation done incrementally. So they needed a smaller number of consultants than company A who may be distributed on different sub modules like GL, AP, AR, CM from Finance and so on.

For Company $\mathrm{C}$ which applied hybrid approach, the implementation is also incremental by implementing sub module instead of complete module like GL from Finance module. So they needed to the smallest number of consultants.

\subsection{ERP Implementation Quality}

The evaluation of quality factors is conducted through questionnaire fulfilled by the ERP users in the three companies.

Table 7 illustrates the results of questionnaire to identify how implementation approaches affect some quality factors like: Learning, Practical test, Knowledge transfer, and User satisfaction.

Table 7: Questionnaire Results

\begin{tabular}{|c|c|c|c|c|c|c|c|c|c|}
\hline \multirow{2}{*}{ Factor } & \multicolumn{3}{|c|}{ Company A } & \multicolumn{3}{c|}{ Company B } & \multicolumn{3}{c|}{ Company C } \\
\cline { 2 - 11 } & $\mathrm{VG}^{*}$ & $\mathrm{G}^{* *}$ & $\mathrm{~B}^{* * *}$ & $\mathrm{VG}$ & $\mathrm{G}$ & $\mathrm{B}$ & $\mathrm{VG}$ & $\mathrm{G}$ & $\mathrm{B}$ \\
\hline Learning & 4 & 5 & 27 & 10 & 30 & 4 & 30 & 8 & 1 \\
\hline Practical Test & 0 & 7 & 29 & 33 & 11 & 0 & 28 & 11 & 0 \\
\hline $\begin{array}{c}\text { Knowledge } \\
\text { transfer }\end{array}$ & 0 & 3 & 33 & 4 & 40 & 0 & 24 & 7 & 8 \\
\hline User Satisfaction & 0 & 23 & 13 & 35 & 9 & 0 & 27 & 10 & 2 \\
\hline * VG: Very Good & $* *$ G: Good & $* * *$ B: Bad & & & & & & \\
\hline
\end{tabular}

* VG: Very Good ** G: Good *** B: Bad 
A Weighted Average (W.A) formula is used to present the results, and the results are summarized in figure 15.

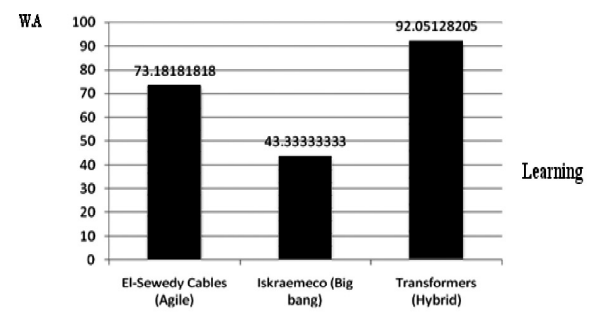

Figure 15.a learning factor

WA

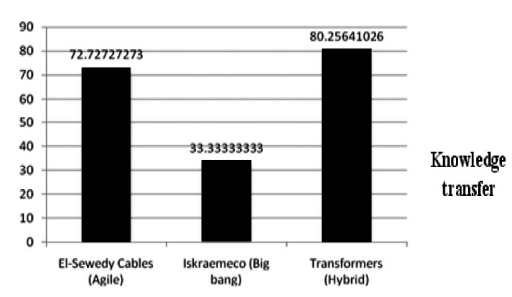

Figure 15.c knowledge transfer factor

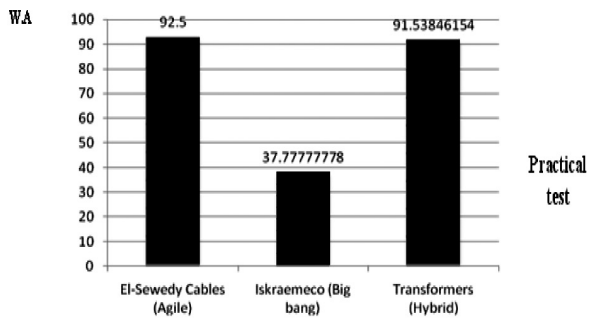

Figure 15.b practical test

WA

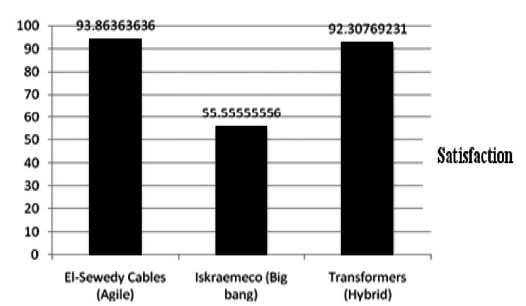

Figure 15.d User satisfaction factor

Figure 15: ERP Implementation Quality Factors

\section{Conclusion}

There are many disadvantages for ERP implementation approaches, we exerted big effort to solve these disadvantages and introduced an improved implementation approach that combines between Agile approach and Big bang approach to solve disadvantages in agile approach and big bang approach such as using a huge amount of interface programs, using a huge amount of resources, cost and risk. This approach is called a hybrid ERP implementation approach. To implement this methodology, we needed to establish ERP dependency diagram to show the inputs for each module and the outputs from each module. To demonstrate the benefits from the hybrid implementation approach, an assessment method was developed to compare the implementation approaches from thee perspectives: Implementation time, implementation cost and implementation quality. By applying the assessment method using a comprehensive case study, the benefits from the hybrid approach was validated and characterization of the different implementation approaches was presented. The experimental results 
showed that Agile approach is the worst approach in implementation time and Hybrid approach reduces the implementation while Big Bang provides the shortest implementation time. Concerning implementation cost, the experimental results showed that Big bang approach has the highest cost and Hybrid approach has the lowest cost. Concerning implementation quality, the experimental results illustrated also that Big bang approach has the lowest quality and Hybrid approach has the best quality. The Hybrid implementation approach has advantages such as reducing amount of interfaces, reducing cost, no need for using a high peak of resources, low risk, and personnel will gain knowledge per iteration. Hybrid implementation approach is based mainly on priority of organizational business requirements.

\section{References}

[1] A.N. Parr, School of Business, Monash University Clayton Victoria 3168, Australia, "a Taxonomy of ERP Implementation Approaches", Hawaii International Conference on System Sciences, 2000.

[2] ERP Life Cycle, "Implementation and Operation and Maintenance", Chapter 6, pp 1-15, 2010.

[3] Jose M. Esteves, Joan A. Pastor, "An ERP Life-cycle-based Research Agenda", International workshop in Enterprise Management and Resource Planning: Methods, Tools and Architectures- EMRPS'99”, Venice, Italy, 1999.

[4] Sindos, Thessaloniki, Greece, "Evaluating the ERP Implementation Project", European Journal of Information Systems (2001).

[5] Jisc infoNet, 'Good Practice and Innovation', 2008. http://www.jiscinfonet.ac.uk/InfoKits/systemimplementation/planning/implementation-models, '3-DEC-2011'

[6] Ken Eason, 'Information technology and organizational change', Taylor \& Francis Inc., 1988.

[7] Koop, R., Rooimans R., and de Theye, M. (2003) Regatta: 'ICT-implementaties als uitdagingeen vier-met-stuurman', S.D.U. Uitgeverij, 2003.

[8] Scott, J.E., Vessey,i., 'implementing enterprise resource planning systems: the role of learning from failure, information systems frontiers', vol.2, 2000, pp.213-232.

[9] SAP Group, Agile: “Implementing SAP step by step”, 2010. 
[10] Jiang Yingiie, 'Critical Success Factors in ERP Implementation in Finland', Thesis in Accounting, The Swedish School of Economics and Business Administration, 2005, pp.7-8.

[11] Daniel O’Leary, "Enterprise Resource Planning Systems: Systems, Life Cycle, Electronic Commerce, and Risk", New York: Cambridge University Press, 2000.

[12] Alexis Leon, "ERP DEMYSTIFIED $2^{\text {nd }}$ Edition", Tata Mc Graw Hill Publishing Co-2008 edition, part III, pp. 209-212.

[13] Amr Ahmed Fetouh, Dr. Ramadan Moawad, Dr. Ahmed el Abassy, “Applying Agile Approach in ERP implementation", IJCSNS International Journal of Computer Science and Network Security, VOL.11 No.8, August 2011.

[14] Ada Wong, Harry Scarbrough, Patrick Y.K. Chau and Robert Davison, "Critical Failure Factors in ERP Implementation", Pacific Asia Conference on Information Systems, 2005

[15] Glen B. Alleman, "Agile Project Management Methods for ERP: How to Apply Agile Processes to Complex COTS Projects and Live to Tell About It", In Extreme Programming and Agile Methods: XP/Agile Universe 2002, pp. 70-88, Springer Verlag, LNCS 2418, Editors, Don Wells and Laurie Williams.

[16] Björn Johansson, "ERP SYSTEMS IMPLEMENTATION: FACTORS NFLUENCING SELECTION OF A SPECIFIC APPROACH?" , 3g ERP workshop 2008.

[17] Gerard Meszaros, Janice Aston, " Agile ERP: "You don't know what you've got 'till it's gone!", ACM digital library, Published in: Proceeding AGILE '07 Proceedings of the AGILE 2007

[18] Sanjay Jharkharia, "Interrelations of Critical Failure Factors in ERP Implementation: An ISM-based Analysis", 3rd International Conference on Advanced Management Science, IPEDR vol.19 (2011) (C) (2011) IACSIT Press, Singapore, 2011

[19] Nair S., Uma, Saji, K.B., "Costing model choice in ERP implementation: an exploratory investigation", European Journal of Management, Spring, 2011 Source Volume: 11 Source Issue: 1,International Academy of Business and Economics.

[20] Aisha Momoh, Rajkumar Roy, Essam Shehab, "A Work Breakdown Structure for Implementing and Costing an ERP Project", Communications of the IBIMA, Volume 6, 2008

[21] "Oracle AIM (Applications Implementation Methodology)", Oracle Corporation. 